\title{
Urbanization, productivity, and innovation: Evidence from investment in higher education is
}

\author{
Roland Andersson $^{\mathrm{a}}$, John M. Quigley ${ }^{\mathrm{b}, *}$, Mats Wilhelmsson ${ }^{\mathrm{a}}$ \\ a Royal Institute of Technology, Stockholm, Sweden \\ ${ }^{\mathrm{b}}$ University of California, 2607 Hearst Avenue, Berkeley, CA, USA
}

\section{A R T I C L E I N F O}

\section{Article history:}

Received 26 September 2008

Revised 12 February 2009

Available online $\mathrm{xxxx}$

\begin{abstract}
A B S T R A C T
During the past two decades, Swedish government policy has decentralized post-secondary education throughout the country. We investigate the economic effects of this decentralization policy on the level of productivity and innovation and their spatial distribution in the national economy. We find important and significant effects of this investment policy upon economic output and the locus of knowledge production, suggesting that the decentralization has affected regional development through local innovation and increased creativity. Our evidence also suggests that aggregate productivity was increased by the deliberate policy of decentralization. Finally, we estimate the spillovers of university investment over space, finding that they are substantial, but that they are greatly attenuated. Agglomerative effects decline rapidly; roughly half of the productivity gains from these investments are manifest within 5$8 \mathrm{~km}$ of the community in which they are made.
\end{abstract}

(ㄷ) 2009 Elsevier Inc. All rights reserved.

\section{Introduction}

Sweden undertook a conscious spatial decentralization of its system of higher education beginning in 1987. This policy was motivated by a complex variety of political, social, and economic factors. In this paper, we analyze the effects of university research activity on economic productivity and upon the level and distribution of innovative activity in the economy. We provide quantitative evidence on the effects of the decentralization policy upon output per worker and upon the award of commercial patents for innovations and discoveries. We also provide new evidence that the policy has increased aggregate productivity and economic output, but that the economic impacts are greatly attenuated over space and distance.

From a broader perspective, there has been intense debate in developed countries about the role of university research, and the spin-offs of that research, in stimulating regional development. The popular press in Sweden has documented - endlessly it seems - the role of Stanford and Berkeley in fostering the

\footnotetext{
A preliminary version of this paper was presented at the NBER Summer Institute and at seminars at UBC, Berkeley, Wharton, JIBS, and the Federal Reserve Bank of New York. The paper benefited from the comments of Raj Chetty, Gilles Duranton, Bronwyn Hall, Matthew Kahn, Jean Lanjouw, David Mowery and Brian Wright and from the able assistance of Henry Hyatt. We are especially grateful for the detailed comments of Caroline Hoxby and William Strange, and of two very thoughtful referees.

* Corresponding author.

E-mail addresses: roland.andersson@infra.kth.se (R. Andersson), quigley@econ.berkeley.edu (J.M. Quigley), mats.wilhelmsson@infra.kth.se (M. Wilhelmsson).
}

growth of the Silicon Valley in Northern California. One implication seems to be that investment in post-secondary education affects the aggregate level of economic activity as well as its geographical distribution.

A related line of research has sought to understand more generally the economic role of space in affecting economic growth and increased productivity. Recent theories have stressed the role of knowledge spillovers in cities in generating growth, distinguishing between spillovers among firms within an industry (Marshall-Arrow-Romer externalities) and spillovers across industries arising from the colocation of economic activity in cities (Jacobs externalities). Work by Glaeser et al. (1992) is consistent with the importance of industrial diversity (rather than concentration) in fostering economic growth in the US. In contrast, Henderson et al. (1995) find that concentration facilitates growth in mature capital-intensive industries.

The precise linkages among educational investments, knowledge, spillovers and regional output remain unclear, and, in the words of Jaffe (1989), the "transport mechanism" is not well understood. The work of Romer (1986, 1990), Lucas (1988), and especially Fujita (1988) suggests that these external economies from concentration are endogenous outcomes caused by the colocation of firms and workers. In any case, it is now quite natural to recognize "productivity gains from the geographical concentration of human capital" (Rauch, 1993). This line of research is reviewed by Moretti (2004).

One specific mechanism linking educational investment to regional output is innovation itself. If educational investment stimulates local innovation and creativity, productivity gains may arise 
from the new knowledge whose production is facilitated by the pattern of spatial investment (Jaffe et al., 1993). We analyze this mechanism using the natural experiment of decentralization of higher education in Sweden. We trace the implications of this exogenous change in policy upon productivity and upon the level and distribution of innovative activity in the national economy. In conducting this analysis, we rely upon unique bodies of data annual estimates of output per worker for each of 284 local civil divisions in Sweden and comprehensive records on patent awards, which include the home address of the inventor.

Our results document the surprisingly large effects of these specific university investments in stimulating creativity and regional productivity. We quantify the importance of university research in the production of patents, although we cannot distinguish between the direct activities of a university and its ancillary role in inducing the nearby location of research-intensive industry. Our results also document the effects of university investments on local economic activity, especially increases in output and worker productivity. To be sure, we cannot distinguish fully between the direct and the induced effects of university investment on patents and productivity. From the viewpoint of the localities receiving the investment, it matters little whether the local university produces graduates of higher productivity who will work in the region or whether more productive firms are induced to work in the region by the presence of the educational facility.

But this distinction is crucial from a societal viewpoint. In this instance, we can estimate the net effect of the spatial rearrangement of economic activity upon aggregate output. When our statistical results are used to compare the economic effects of increased university investment in the pre-existing institutions (in older, denser, urban regions) with equivalent investments in new institutions (in less dense, less urbanized regions), the results suggest that the decentralization policy has led to an increase in aggregate output and aggregate creativity. The estimated effects are not large, but they persist across specifications and statistical models. These results are consistent with recent work by Rosenthal and Strange (2003, 2005, 2008) which suggests that external economies of agglomeration are sharply attenuated with distance and that the marginal effects upon agglomeration of additional employees at small new establishments are larger than the economic effects of equivalent investments at traditional locations. Our results are also consistent with those reported by Arzaghi and Henderson (2006) for New York City - which suggest significant productivity gains from the collocation of firms in Manhattan, but gains which attenuate rapidly over space.

An earlier paper, Andersson et al. (2004), hints at some of these findings about university investment policy. That work, based on more primitive data and statistical methods, suggested a linkage between university investment and economic output. Previous work did not investigate patent activity as a transmission device or the attenuation of economic effects over space.

Section 2 provides a brief review of Swedish university policies and innovation during the last few decades. Section 3 surveys the literature on university research, knowledge spillovers, and innovation as they affect economic growth. Section 4 presents the data and the models used in our statistical analysis. Section 5 summarizes our results and conclusions.

\section{Swedish university policy}

As recently as 1977, only six universities operated in Sweden, a country of nine million people about the size of California. The locations of these institutions, the old established universities

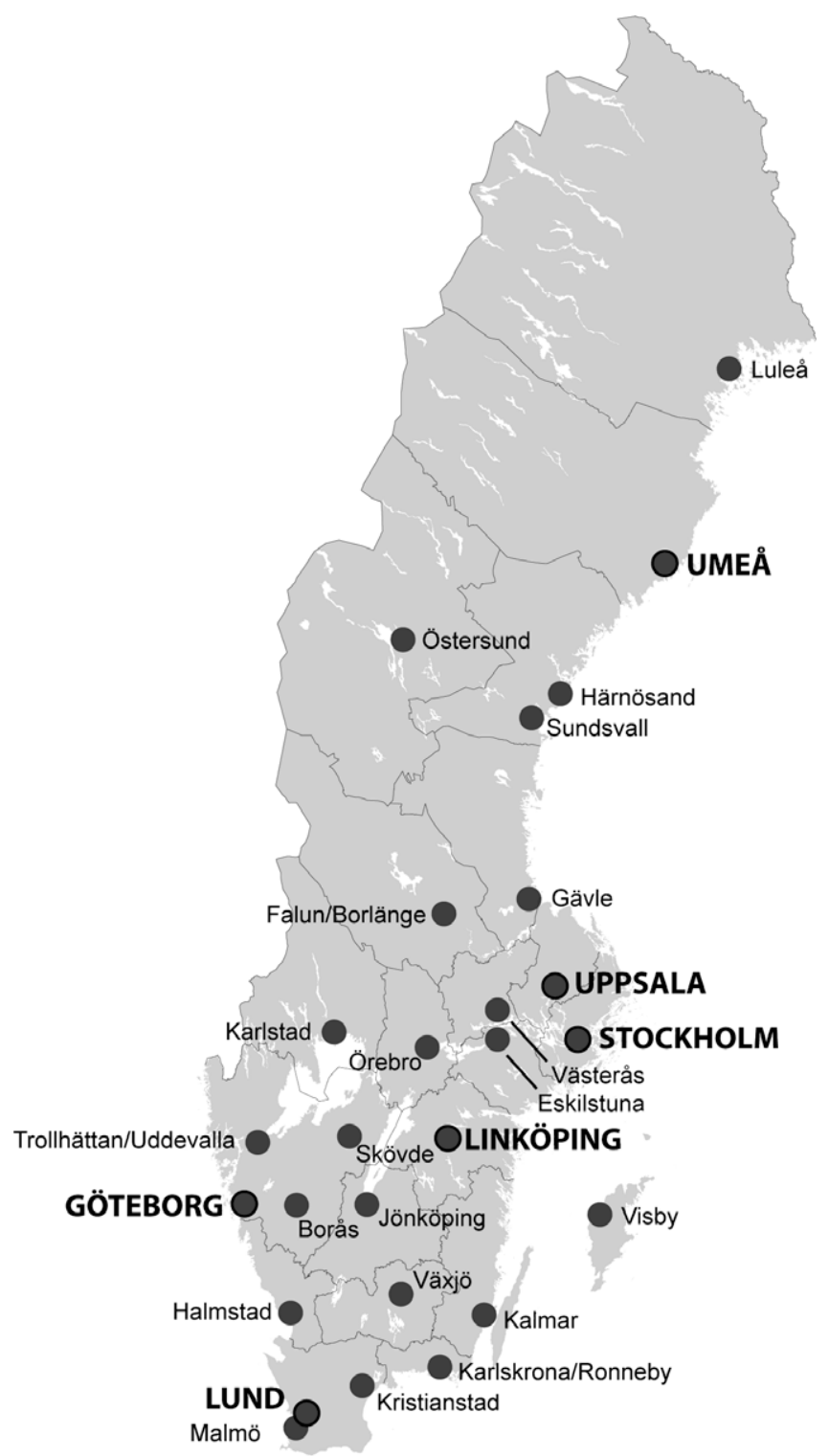

Fig. 1. Location of "old" and "new" universities in Sweden. Note: Locations of "old" institutions in boldface.

and five technical institutes, ${ }^{1}$ are depicted in Fig. 1 . In addition, 14 small colleges existed; each was affiliated with a university. In 1977, the university structure was changed, establishing 11 new institutions, raising the status of the 14 colleges and placing all 36 universities, institutes and colleges (located in 26 different municipalities) under one administration. The "new" university structure is also indicated in Fig. 1.

In almost all cases, the sites chosen for the new institutions of higher education were formerly occupied by teacher training schools, engineering academies, or by military training facilities. ${ }^{2}$ In the review of this expansion of the university system prepared by the National Agency for Higher Education ("Hogskoleverket") in

\footnotetext{
${ }^{1}$ Universities were located in Stockholm, Göteborg, Lund, Uppsala, Linköping, and Umeå. In addition, there were three large technical institutes in Stockholm (The Royal Institute of Technology; the Karolinska Institute of Medicine; and the Stockholm School of Economics), as well as two others (The Chalmers Institute of Technology in Göteborg and the Institute of Agriculture near Uppsala).

2 Five sites of university expansion formerly housed institutions of preschool education; eight formerly housed affiliates of Sweden's Institute of Education; two had been schools of naval science (several sites had housed more than one of these facilities)
} 
1998 , only one instance is reported in which economic considerations affected the location chosen for a new institution. ${ }^{3}$ of course, this review was prepared ex post by the government agency that supervised the expansion, and there may have been political or partisan reasons for this characterization. ${ }^{4} \mathrm{~A}$ review of the parliamentary acts establishing the new universities also gives short shrift to the role of local fiscal policy in the choice of locations for the new universities. ${ }^{5}$ But, for the parliament as well as for the government agencies, increased student access may simply be a rationale for the public investments. In recent interviews with participants in the expansion process, undertaken in response to reviewer comments, we found little evidence that local fiscal policy affected the choice of location for the institutions. ${ }^{6}$

Of course, none of this really proves that the locations of the new institutions were not chosen primarily to employ idle resources, and alternative explanations should be borne in mind. ${ }^{7}$ However, it is worth noting that during the period 1968-1976 (before the policy was undertaken) municipalities in which the new institutions were located grew by $4.9 \%$ in population. Municipalities in which the old institutions were located declined by $4.3 \%$. Population increased by $6.3 \%$ in the remaining cities in Sweden. During the period 1977-1999 (after the policy was introduced), the cities in which the new institutions were located grew by $4.6 \%$ in population; cities in which the old institutions were located grew by $1.4 \%$. The remaining cities in Sweden increased by $7.1 \%$ in population. ${ }^{8}$

\footnotetext{
${ }^{3}$ The college established in Karlskrona-Ronneby was in an area of high unemployment caused by the closing of a major shipyard. In all other cases, the new colleges were located to replace or upgrade existing post-secondary school and teacher-training activities. See De första 20 åren (1998), for an extensive discussion.

${ }^{4}$ One reviewer suggests that this may simply be the "preferred public version of the events."

${ }^{5}$ For example, in the enabling legislation for the initial expansion (Government Proposition 1976/77: 59), the explicit aim of increasing the opportunities for a socially and geographically diverse student body was stressed. ("En hogskoleenhet $i$ varje ort," roughly "a unit of higher education in every locality," was the slogan.) In subsequent legislation (e.g., Propositions in 1986/87 and 1987/88), there is no reference to local fiscal policy as a motive, but in more recent legislation (Proposition 1996/97), there is one reference to the unemployment rate in Malmo at the time that the higher education facility was authorized.

${ }^{6}$ On the contrary, an interview with a senior official in the budget office at the time of the university expansion revealed that the Budget Minister himself intervened in the localization process to diminish the average distance of these new institutions from concentrations of potential students, referring specifically to the motive of increasing the low recruitment rates to higher education in regions without universities. (Interview with Anders Lundin by Roland Andersson on December 20 2008.) In another recent interview, Erland Ringborg stressed that the reason for the locational choices for new institutions was to increase student access. Educational institutions for school teachers were already spread out geographically under an existing administration in the Ministry of Education, and this facilitated the decentralization of the new institutions of higher education to those locales (Ringborg was one of the architects of the 1977 reform and ultimately served as undersecretary in the Ministry, 1982-1986. Interview by Roland Andersson on February 3, 2009.)

One reader, for example, suggested that the localization decisions could have reflected "pork barrel" politics. But this, by itself, would not have had the effects on productivity and innovation we find in the analysis below.

8 Published data on employment by municipality go back only to 1985 , but (as indicated in Fig. 2 below) there were practically no research staff at the new universities in 1985. In any event, in 1985 the employment rate (employment divided by adult population) in the municipalities with a new university was $51.3 \%$. In municipalities with the old institutions, the rate was 51.9\%. In the remaining cities in Sweden, the rate was $49.7 \%$. The rate of increase in employment between 1985 and 1986 was $0.6 \%, 0.8 \%$, and $0.6 \%$, respectively, for the three groups of cities. Ultimately, we were able to get a special tabulation of employment data conforming to current municipality boundaries from Statistics Sweden going back to 1960. These unpublished data provide no evidence that the employment rates or changes in employment rates were lower in municipalities which received new institutions than in those which did not. (Employment rates in municipalities with a new institution were $44.5 \%, 44.1 \%, 47.7 \%$, and $49.9 \%$ in $1965,1970,1975$, and 1980 while they were $39.4 \%$, $37.7 \%, 39.5 \%$, and $46.6 \%$ in municipalities with no university.) Annual changes in employment averaged $9.3 \%, 4.7 \%, 10.0 \%$, and $5.0 \%$ in the former municipalities in $1960-1965,1965-1970,1970-1975$, and $1975-1980$, respectively, and $13.5 \%, 4.6 \%$, $8.4 \%$, and $6.4 \%$ in the latter municipalities.
}

Despite the change in status, the new institutions of higher education developed relatively slowly during the first decade after reorganization. Thus, the number and distribution of students between the older institutions and the newly established colleges of higher education was about the same in 1987 as it had been in 1977. However, beginning in 1987, there was a substantial expansion. During the subsequent period, the number of students at the newer colleges more than doubled while the number of students at the older universities increased half again. Moreover, the resources for research at the newer institutions were increased substantially, particularly during the decade of the 1990s. By 1998 , the newly established institutions had grown to a total of 84,000 students, and more than a third of all the students enrolled in higher education attended one of these institutions.

The motives for rapid decentralization were political and social as much as economic. One important motivation for the establishment of these new colleges was the desire to make undergraduate education geographically more accessible in all parts of Sweden. A related motivation was to increase the representation in higher education of students from areas geographically more remote from the established universities. The policy also sought to increase the access to higher education of different social classes, especially those for which higher education has not been a tradition. Proponents of this decentralization also claim that the policy favors those who would like to stay, to live, and to work locally. A premise of this regional policy is that the allocation of resources to the newer regional colleges would increase not only the local educational level, but also the number of jobs in these regions (Andersson, 2005). Many of these same arguments are familiar in other contexts, for example, California's decision to establish a new university campus inland in Merced and British Columbia's decision to establish new university campuses at Prince George, 490 miles north of Vancouver, and at Kelowna, 250 miles inland.

The university decentralization can be interpreted simply as Keynesian fiscal policy at the regional level. ${ }^{9}$ Two other potential effects of this policy can be identified. The first is an expectation that the enhanced institutions would provide spillovers or local externalities that could improve productivity and lead to regional expansion by existing companies or by start-up firms. Alternatively, research at a regional college or university could foster directly innovation and increased entrepreneurial activity - the "Silicon Valley model."

of course, these latter effects are not mutually exclusive. Exogenous changes in the distribution of university resources may induce spillovers among firms, leading to increased productivity and economic output directly. Increased innovative activity represents one mechanism by which regional output and creativity could have been increased.

In Section 4, below, we investigate these connections, analyzing the changes in productivity induced by these investments and the subsequent changes in the spatial distribution of innovative activity and the level of creativity in the economy. It is surely true that there are lags between investments in research staff, facilities, and resulting levels of innovation. There are further lags between creative output, its embodiment in a patent granted after review, and its effects on productivity and economic output. Even beyond any lags in observing responses, the complementarity between the specialties chosen for education and research by the various regional colleges (science, technology, social science, etc.) and the economic activities in the region probably matters in generating innovative activity. We investigate these issues.

\footnotetext{
${ }^{9}$ Direct expenditures will increase employment and economic output, and the construction and operation of new facilities will induce more economic activity through the local multiplier (see Florax, 1992).
} 


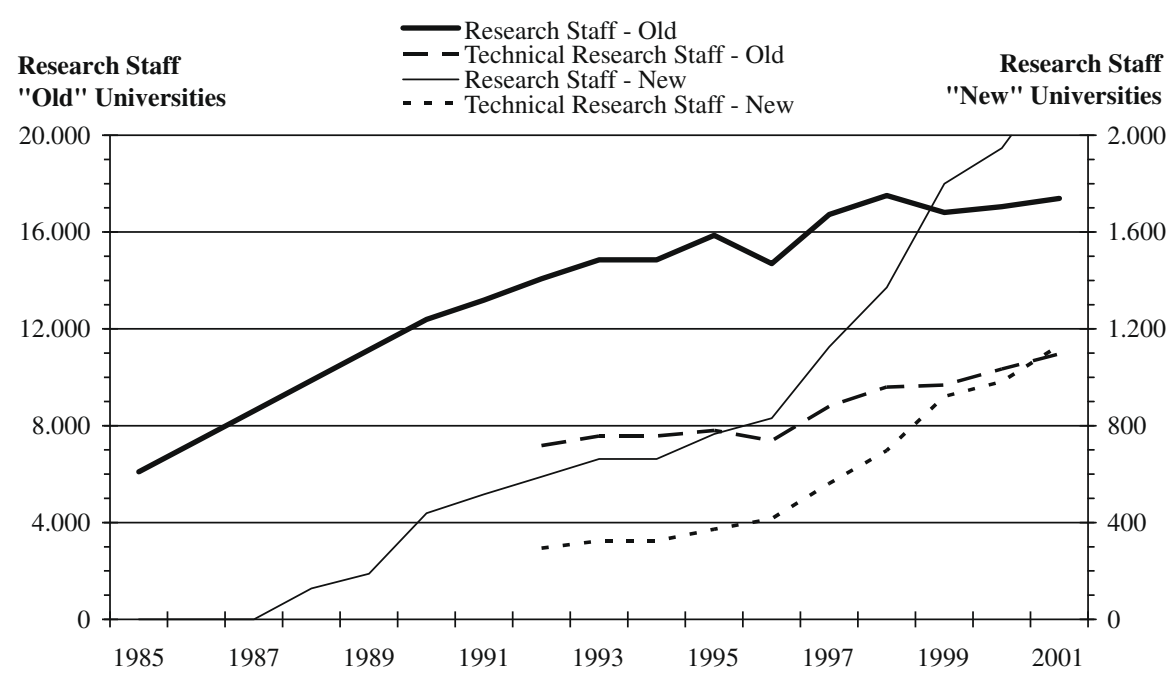

Fig. 2. Post-graduate research staff at Swedish universities, 1985-2001. Note: Technical research staff (our calculations) is not available separately before 1992.

\section{University research, production, and innovation}

Marshall (1890) first drew attention to the economic effects of agglomeration and external scale economics, arguing that clustered firms increased output and the productivity of inputs. Externalities flowing from human capital in regional development had a scientific revival with the endogenous growth models of Romer (1986, 1990), Lucas (1988), and Grossman and Helpman (1991). Griliches $(1979,1998)$ and Jaffe $(1986,1989)$ have modeled this effect in a simple production function framework using industry and university research as inputs.

As Marshall and later Krugman (1991), Feldman (1994), Jaffe et al. (1993), Audretsch and Feldman (1996), and others have emphasized, space itself forms a barrier to the diffusion of knowledge. Daily face-to-face contact may be quite important in the diffusion of results from scientific research and development (R\&D). It may thus be beneficial for commercial developers to locate close to universities and other centers of basic research. However, geographic proximity to other firms in the same industry may be of even greater importance in stimulating applied research and innovations which improve practice. Florax (1992), however, found that proximity to a college or university is not a significant factor in explaining regional variations in the incidence and location of new start-up companies.

During the last two decades, data on patents have been relied upon increasingly in investigating the production of knowledge (See Griliches, 1984). ${ }^{10}$ Using patent counts, Acs et al. (2002) found that both university research and private R\&D exerted substantial effects on innovative activity and patents across US metropolitan areas, with a clear dominance of private $R \& D$ over university research.

Jaffe (1986) investigated the link between patents and the R\&D activities of firms. His research suggests that knowledge transfers occur more easily among companies in regions with a high output of patents. Companies performing research in areas where a considerable amount of research is carried out by other companies also appear to generate more patents per dollar spent on R\&D than

\footnotetext{
$\overline{10}$ In his 1990 survey paper, Griliches observed that a patent represents "a minimal quantum of invention that has passed both the scrutiny of the patent office as to its novelty and the test of the investment of effort and resources by the inventor ( $p$. 1669)." He emphasized that patents comprise only a subset of all inventions, since a great many valuable inventions are not patented. More recently, Jaffe and Trajtenberg (2002) caution that citation-weighted patent counts are a better measure of the value of patents than simply patent counts.
}

companies located in areas where relatively little research is carried out by other companies. Thus, clusters of research companies facilitate the diffusion of new knowledge. Jaffe (1989) analyzed time series data on corporate patents for US states, corporate $\mathrm{R} \& D$, and university research, investigating spillovers from academic research. He found a significant effect of university research on corporate patents. His results also suggested that university research may have an indirect effect on local innovation by inducing R\&D spending by private firms. ${ }^{11}$

Varga $(1998,2000)$ related the output of $R \& D$ (measured by regional registrations of more than 4000 product innovations) to annual expenditures on university research as well as the number of employees in laboratories and research institutes within private companies. Using aggregate data for US states and metropolitan areas, he found important returns to scale and scope. Varga concluded that there is a critical mass relating the density and size of a region to the output of innovative activity. In this process, university inputs "matter."

Fischer and Varga (2003) related patent applications in 99 political districts in Austria to aggregate research expenditures by private firms in those districts and to estimates of university research expenditures in those districts, finding significant effects of inputs on patent applications. The interpretation of the results of this investigation is somewhat problematic, ${ }^{12}$ but they are suggestive of a linkage.

\section{Hypotheses and data}

Our models estimate the effects of university-based researchers on the productivity and innovations of local areas, and they compare the effects for the older established (pre-1977) universities with those for the newer, smaller, and less centralized institutions established since then. Decentralization is measured by the spatial distribution of the post-graduate university research staffs, and productivity is measured by output per worker. Innovative activity is measured by the award of patents by the Swedish Patent and

\footnotetext{
11 Jaffe also points out the limitations of aggregate analyses at the level of US states 12 For example direct university research expenditures were made in only 7 districts, and 27 districts which reported no patents were simply excluded from the analysis. More importantly, patent applications were linked to the geographical location of the assignee rather than the location of the inventor. Thus, the locations of firm headquarters rather than the locations of research establishments or individual inventors were used to allocate the distribution of patents over space.
} 

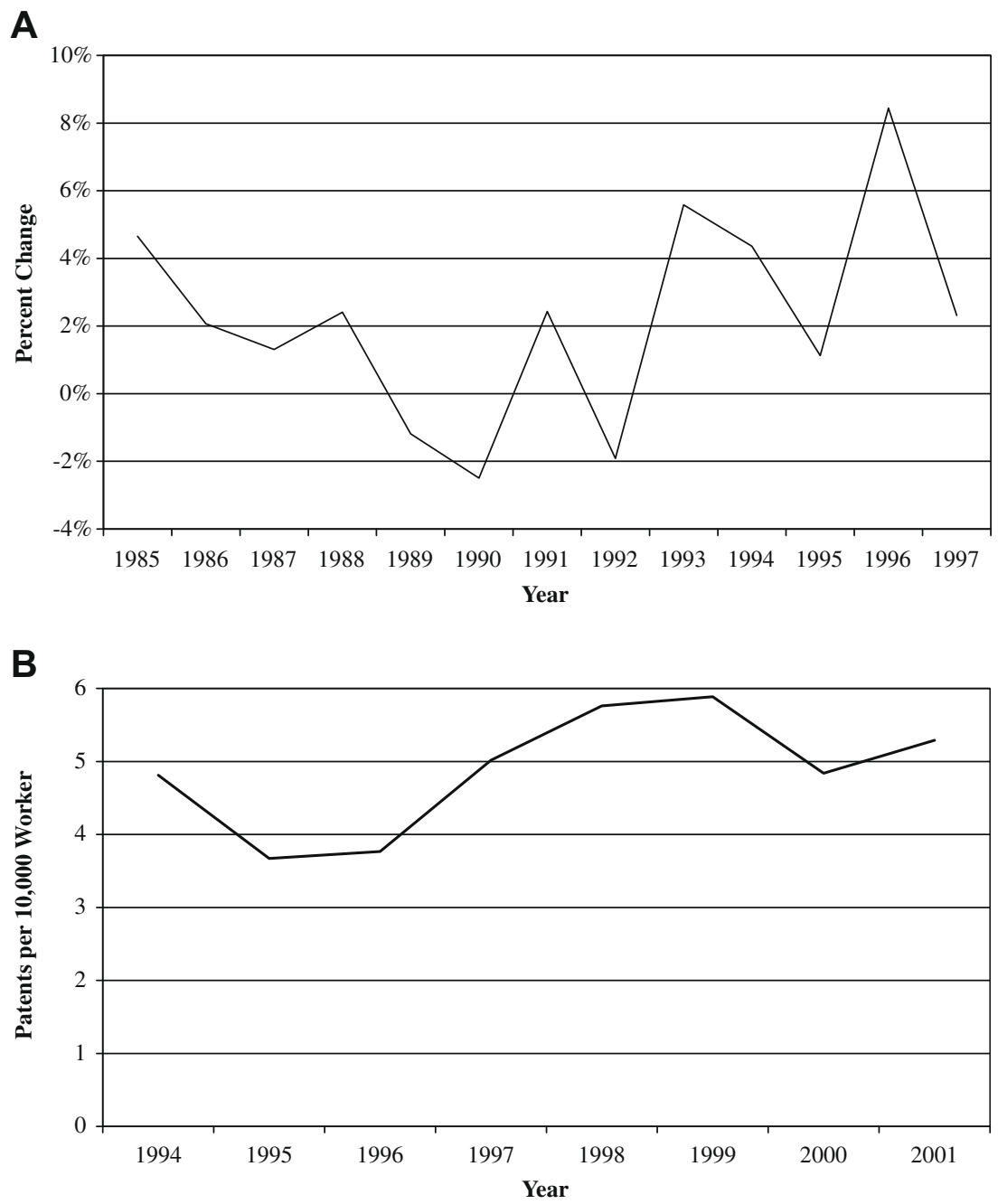

Fig. 3. (A) Annual changes in productivity worker in Sweden, 1985-1997. (B) Annual awards of patents per 10,000 workers in Sweden, $1994-2001$.

Registration Office, which predates the European Patent office and which has more extensive coverage.

As reported in Fig. 2, the number of post-graduate researchers employed in Swedish universities tripled, from 6000 in 1985 to almost 20,000 in 2001 . The $15 \%$ per year increase in the post-graduate research staff includes much larger percentage increases in those employed at the smaller and newer institutions. Currently about one-eighth of research staff positions are located at these new colleges, and the scale of these positions is expected to grow. ${ }^{13}$

During this same period, university enrollment increased by almost $90 \%$, from 160,000 students to 306,000 . There was an increase of roughly 63,000 students in the older established universities and 83,000 students in the newer universities. The capacity of the newer colleges and universities more than tripled to 114,000 students.

During the period beginning in 1985 , annual increases in real output per worker averaged about 2.3\% per year in Sweden, with productivity increases as large as $5.5 \%$ (in 1993) and as low as minus $2.5 \%$ (in 1990). Fig. 3A reports aggregate annual productivity increases during the 1985-1998 period. Annual increases in new knowledge (at least, as measured by commercial patents) also varied significantly. Between 1994 and 2001, about 16,000 commer-

\footnotetext{
${ }^{13}$ It should be noted that the allocation of staff positions is made centrally by the
} Ministry of Education, not by the institutions themselves using "soft money." cial patents were approved. Annual approvals ranged from a low of about 1500 patents granted in 1995 , to a high of almost 2500 patents granted in 2001. Fig. 3B reports the trends in patent awards per 10,000 workers.

The record for each patent award includes both the date of the award and the date of the application. It generally takes about 3 years for a successful application to be approved. In 1994, for example the average time interval from application to award was 2.5 years, and $80 \%$ of approvals were made within 4 years of the initial application. In 2001, the average time interval increased to 2.9 years, and three quarters of approvals were made within 4 years of application.

As noted above, output per worker is recorded annually for each of 284 municipalities. ${ }^{14}$ Patent data record the home address of the innovator(s). Because inventors may live in one municipality and work in another, we allocate each patent to the (geographically larger) labor market area in which the inventor lives. ${ }^{15}$ Fig. 4 provides a

\footnotetext{
14 Gross regional product is estimated by the value-added approach for 45 different business sectors at the municipal level. For a few sectors (for example, the agricultural sector), the income approach is utilized at the national level and is then imputed to the regional level (for example, using acreage in various crops).

15 Labor market areas are defined in terms of commuting patterns much the same as metropolitan statistical areas are defined in the US (except that the basic building block is the municipality rather than the county). In the case of multiple inventors in different labor markets, the allocation of invention to labor market areas can be made proportionately.
} 


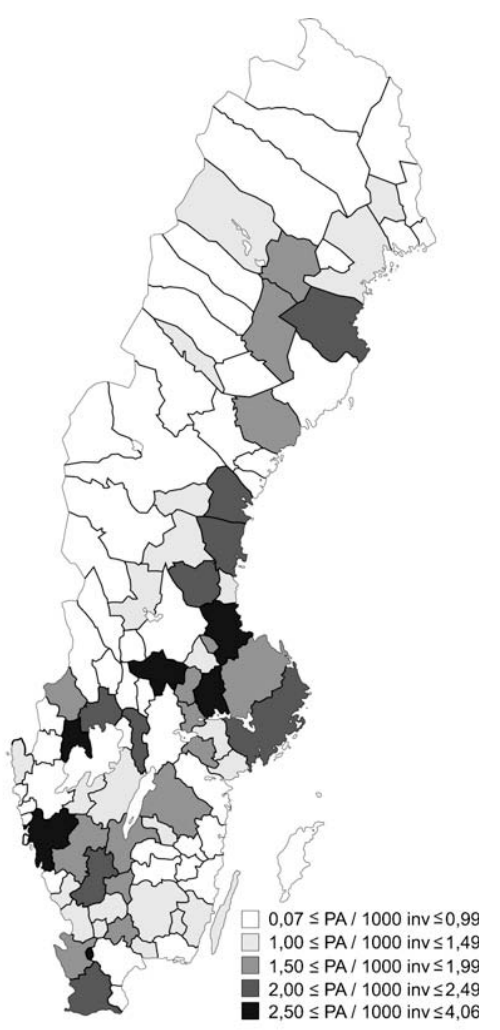

Fig. 4. Patents approved (PA) per thousand inhabitants, 1994-2001. Sites of the old universities are indicated by a black dot.

summary of this allocation process. For each of the 100 labor market areas in Sweden, the map indicates the aggregate number of patents per capita awarded during 1994-2001.

Table $1 \mathrm{~A}$ provides a summary of the average productivity in municipalities containing the old universities, in municipalities containing the new universities and in municipalities which do not contain universities or colleges. For each of the comparison years, average productivity is higher in municipalities containing the old institutions than in those containing the new institutions.

Analogously, Table 1B provides a summary of the patents awarded to inventors residing in labor market areas containing the old universities, those awarded to inventors in labor market areas containing the new universities, and those awarded in labor market areas which do not contain universities or colleges. In 1995, there were about 3.8 patents awarded per 10,000 workers in Sweden -4.5 patents per 10,000 workers in labor market areas containing the old universities, 3.4 in labor market areas containing the newly established universities, and 3.0 in labor market areas which do not contain universities or colleges. In 2001, the number of patents increased. However, the same pattern of patents per worker persists in the three types of regions, even though the patents per worker in regions with older institutions increased rapidly.

Of course, many other factors have much larger effects upon productivity and patent activity than the factors identified in the comparisons in Table 1 . For one thing, the largest and most heavily developed metropolitan regions in Sweden are all labor market areas that contain the old established universities. For another thing, the distribution of firms with different patterns of productivity per worker (particularly large chemical and pharmaceutical firms with a great deal of patent activity) is heavily concentrated by city and region.

\section{Statistical models of productivity}

We analyze productivity and patent activity over time and space using a model with fixed effects, that is, indicator variables for each of the municipalities or labor market areas and for each year. In this formulation, the distinctive characteristics of each municipality or labor market area are held constant, as are the distinctive characteristics of each time period. Identification is achieved through changes in productivity and patent activity within geographical areas and years.

First, we analyze the link between university inputs and productivity. In the section that follows, we consider the relationship with patents. Our models estimate the effects of university-based researchers on the productivity of local areas, and they compare the effects for the older, established (pre-1977) universities with those for the newer, smaller, and less centralized institutions established since then. The geographical areas are generally quite small, and our research design attempts to control for potential spillovers across geographical boundaries in a variety of ways. The general form of the model is:

$\log P_{i t}=\alpha E_{i t}+\sum_{j=1}^{284} \beta_{j} M_{j}+\sum_{k=1985}^{1998} \gamma_{k} T_{k}+\varepsilon_{i t}$.

The dependent variable is worker productivity, $P_{i t}$, output per worker, in community $i$ in year $t$. $E_{i t}$ characterizes post-secondary education in community $i$ in year $t . M_{j}$ and $T_{k}$ are fixed effects; $M_{j}$ is a dummy variable with a value of one for municipality $i=j$ and zero otherwise $(i \neq j)$, and $T_{k}$ is a dummy variable with a value of one for year $t=k$ and zero otherwise $(t \neq k) . \alpha, \beta$, and $\gamma$ are estimated parameters, and $\varepsilon$ is an error term.

In our regressions, we measure $E$ by the number of universitybased researchers $(R)$ employed in the community. In other regressions, we distinguish between university-based researchers employed at the 'old' and the 'new' institutions ( $R^{o}$ and $R^{n}$, respectively). In still other models we distinguish those university-based researchers trained in technical specialties.

We estimate several models and variants to account for intercommunity spillovers arising from the economic activity stimulated by investment in post-secondary institutions. In the most straightforward of these extensions, we include a gravity variable summarizing the distance of each community to the universities and university researchers employed in all other communities. In these models, we include an additional variable, $\sum_{j \neq i} R_{j t} / d_{i j}$, where $d_{i j}$ is the distance between community $i$ and community $j$. The gravity measure weights the university research activity in each of the other communities inversely proportional to its distance to that jurisdiction.

We also recognize that the decentralization "experiment" did not employ random assignment in the geographical distribution of new institutions of higher education. The 278 communities and 83 labor market areas without a university at the time of the adoption of the policy were not equally likely to have established a university subsequently.

Although the historical record clearly specifies that the location of only one of the new facilities was chosen for economic considerations, there may be systematic determinants of the choices of locations for these new facilities. For our purposes, the most important issue is whether the sites chosen were those which were poised for economic development and increased patent activity anyway.

To address this issue, we also present estimates of Eq. (1) using a set of instrumental variables. As instruments for the presence of a university and for the number of researchers, we employ a vector of variables indicating whether each of the following kinds of facilities was located in each community prior to the university 
Table 1A

Average productivity by municipalities containing "new" and "old" institutions of higher education (output per worker, thousands of SEK).

\begin{tabular}{|c|c|c|c|c|c|c|}
\hline \multirow{2}{*}{$\begin{array}{l}\text { Year } \\
\text { Measure }\end{array}$} & \multicolumn{2}{|r|}{1985} & \multicolumn{2}{|r|}{1990} & \multicolumn{2}{|r|}{1995} \\
\hline & Productivity & $\begin{array}{l}\text { Change in } \\
\text { productivity }\end{array}$ & Productivity & $\begin{array}{l}\text { Change in } \\
\text { productivity }\end{array}$ & Productivity & $\begin{array}{l}\text { Change in } \\
\text { productivity }\end{array}$ \\
\hline Average & 200 & 19 & 299 & 19 & 405 & 9 \\
\hline $\begin{array}{l}\text { In labor market with } \\
\text { New institutions }\end{array}$ & 194 & 9 & 284 & 14 & 393 & 20 \\
\hline Old institutions & 201 & 19 & 310 & 24 & 425 & 22 \\
\hline Neither new nor old & 202 & 19 & 299 & 18 & 399 & 17 \\
\hline
\end{tabular}

Table 1B

Patents awarded in labor markets containing "new" and "old" institutions of higher education (number of patents).

\begin{tabular}{|c|c|c|c|c|c|c|}
\hline \multirow{2}{*}{$\begin{array}{l}\text { Year } \\
\text { Measure }\end{array}$} & \multicolumn{2}{|r|}{1995} & \multicolumn{2}{|r|}{2001} & \multicolumn{2}{|r|}{ Total 1995-2001 } \\
\hline & Number of patents & $\begin{array}{l}\text { Patents per worker } \\
(0,000)\end{array}$ & Number of patents & $\begin{array}{l}\text { Patents per worker } \\
(0,000)\end{array}$ & Number of patents & $\begin{array}{l}\text { Patents per worker } \\
(0,000)\end{array}$ \\
\hline Average & 1465 & 3.80 & 2231 & 5.43 & 13,934 & 5.03 \\
\hline $\begin{array}{l}\text { In labor market with } \\
\text { New institutions }\end{array}$ & 303 & 3.42 & 488 & 4.13 & 3770 & 4.48 \\
\hline Old institutions & 786 & 4.49 & 1387 & 7.01 & 7805 & 6.03 \\
\hline Neither new nor old & 376 & 3.00 & 356 & 3.75 & 2359 & 3.72 \\
\hline
\end{tabular}

Table 2

Estimates of the effects of universities on productivity, by municipality 1985-1998 ( $t$ ratios in parentheses).

\begin{tabular}{|c|c|c|c|c|c|c|c|c|}
\hline & \multicolumn{4}{|c|}{ OLS estimates } & \multicolumn{4}{|c|}{ IV estimates } \\
\hline & L1 & L2 & L3 & L4 & L5 & L6 & L7 & L8 \\
\hline \multicolumn{9}{|c|}{ A. Log linear models } \\
\hline$R \times 10^{4}$ & $0.561(3.93)$ & $0.592(4.16)$ & & & $0.748(4.03)$ & $0.806(4.32)$ & & \\
\hline$R^{n} \times 10^{4}$ & $4.003(2.85)$ & $4.347(3.10)$ & & & & $8.257(3.58)$ & $8.869(3.84)$ & \\
\hline$R^{o} \times 10^{4}$ & & & $0.532(3.71)$ & $0.561(3.93)$ & & & $0.565(2.91)$ & $0.612(3.14)$ \\
\hline $\mathrm{Gr} \times 10^{4}$ & & $1.998(5.16)$ & & $2.093(5.28)$ & & $4.384(4.91)$ & & $4.533(5.06)$ \\
\hline & L9 & L10 & L11 & L12 & L13 & L14 & L15 & L16 \\
\hline \multicolumn{9}{|c|}{ B. Log-log models } \\
\hline $\ln R$ & $0.016(4.98)$ & $0.017(5.28)$ & & & $0.025(5.54)$ & $0.026(5.74)$ & & \\
\hline $\ln R^{n}$ & & & $0.015(4.72)$ & $0.016(5.01)$ & & & $0.020(4.08)$ & $0.021(4.22)$ \\
\hline $\ln R^{o}$ & & & $0.088(3.43)$ & 0.095 (3.69) & & & $0.117(2.82)$ & $0.124(2.96)$ \\
\hline $\ln \mathrm{Gr}$ & & 2.045 (5.29) & & $2.093(5.41)$ & & 4.362 (4.89) & & $4.417(4.96)$ \\
\hline
\end{tabular}

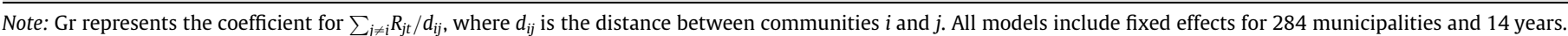
The sample consists of a panel of 3976 observations on output per worker by municipality and year.

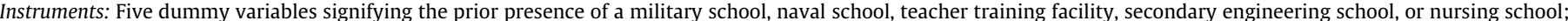

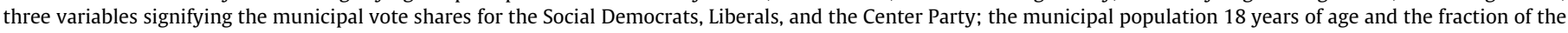

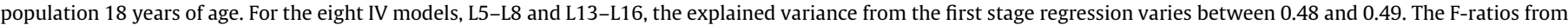

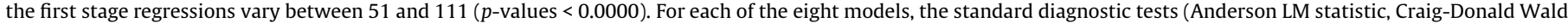
F-ratio, Sargan statistic) all have $p$-values less than 0.0000 .

expansion: military facilities; nursing schools; secondary engineering schools; and preschool teacher training facilities. Students at these facilities have a negligible effect upon current productivity, but the presence and scale of these facilities do affect the ease of expanding university presence into any community (see note 2 above). In addition, we include as instruments the number and proportion of the population of each community turning 18 years of age in each year (and thus becoming eligible for higher education). We also include as instruments the proportion of voters choosing the Social Democrats, the Liberal Party, and the Center Party in each year. ${ }^{16}$ The Social Democrats controlled the national government during this period, and the Minister of Education was a member of that party. The Center Party heavily represents rural interests and was strongly in support of the decentralization policy. These instruments may help explain the extent of university decen-

\footnotetext{
16 These proportions are interpolated from national and municipal elections held in 1985, 1988, 1991, 1994, and 1998.
}

tralization across geographical regions, but they are hardly direct causes of productivity variations. ${ }^{17}$

Table 2 reports the coefficients of these models, ordinary least squares regressions and instrumental variables estimates. Panel A reports estimates of the log linear specification in Eq. (1). Panel B reports the results using a logarithmic specification (and incrementing the number of researchers by one, e.g., $\log [R+1]$, etc.). The OLS models clearly indicate a link between the number of university researchers in a community and the output per worker in that community. This productivity link is highly significant for post-graduate researchers employed at both the old and the new educational institutions. However, the coefficient indicating the

\footnotetext{
17 It would have been nice (for the researchers) if the Education Ministry had employed an explicit rating system and cutoff criteria in selecting sites for the newly established institutions (thereby facilitating a direct identification strategy analogous to that employed by Greenstone et al., 2008). The relevant document, De Första 20 åren, does discuss the selection of sites and does indicate the relevance of pre-existing public facilities, but it does not provide evidence of an explicit scoring system used to determine the sites of new institutions.
} 
importance of post-graduate researchers is about eight times as large for the new institutions as for the older institutions. The pattern is unchanged when the distances among municipalities are controlled for in a gravity representation. But these latter models do suggest that there are spillovers across communities in the productivity linkages; university post-graduate researchers in one community also increase productivity in neighboring communities.

The results from the IV estimates are quite similar. These latter estimates utilize only pre-determined data on the location of infrastructure suitable for conversion to facilities for higher education, on political proclivities and demographics. The results provide no evidence that the locations chosen for university expansion were those which were otherwise poised for economic development and, presumably, for increased patent activity as well. In any case, the qualitative results are quite consistent across specifications.

Fig. 5 provide a non-statistical summary of these results. Fig. 5 plots the average productivity in those communities which received a new university and a post-graduate research staff together with those communities which did not receive a university. Productivity in each community is measured relative to its value in 1988. Fig. 5 compares the productivity of three groups of communities: those in which a new university was established; those in which a university had previously been established; those without a university. From either figure, it seems clear that output per worker in a community increased after the establishment of the university in that community. Trends in productivity in the communities with newly established universities are quite similar to those with the older established universities. Productivity trends in communities without a university are lower.

The IV results in Table 2 give this a more precise interpretation. The coefficients of model L8 suggest that the introduction of 100 additional post-graduate researchers in a newly established university augments local productivity by $4.5 \%$ while the introduction of the same number of researchers in communities containing older established universities augments productivity by $0.5 \%$. The introduction of 100 additional researchers in a community $10 \mathrm{~km}$ away increases local productivity by $2.4 \%$. These effects are precisely estimated.

The differential effects of additional university researchers at "new" and "old" institutions on productivity are consistent across models, and they do not arise simply as an artifact of the log linear specification of Eq. (1). For example, according to the simplest OLS model, L3, with a log linear specification, an augmentation of 100 post-graduate researchers at an older established university increases productivity by $0.5 \%$ while the equivalent investment at a
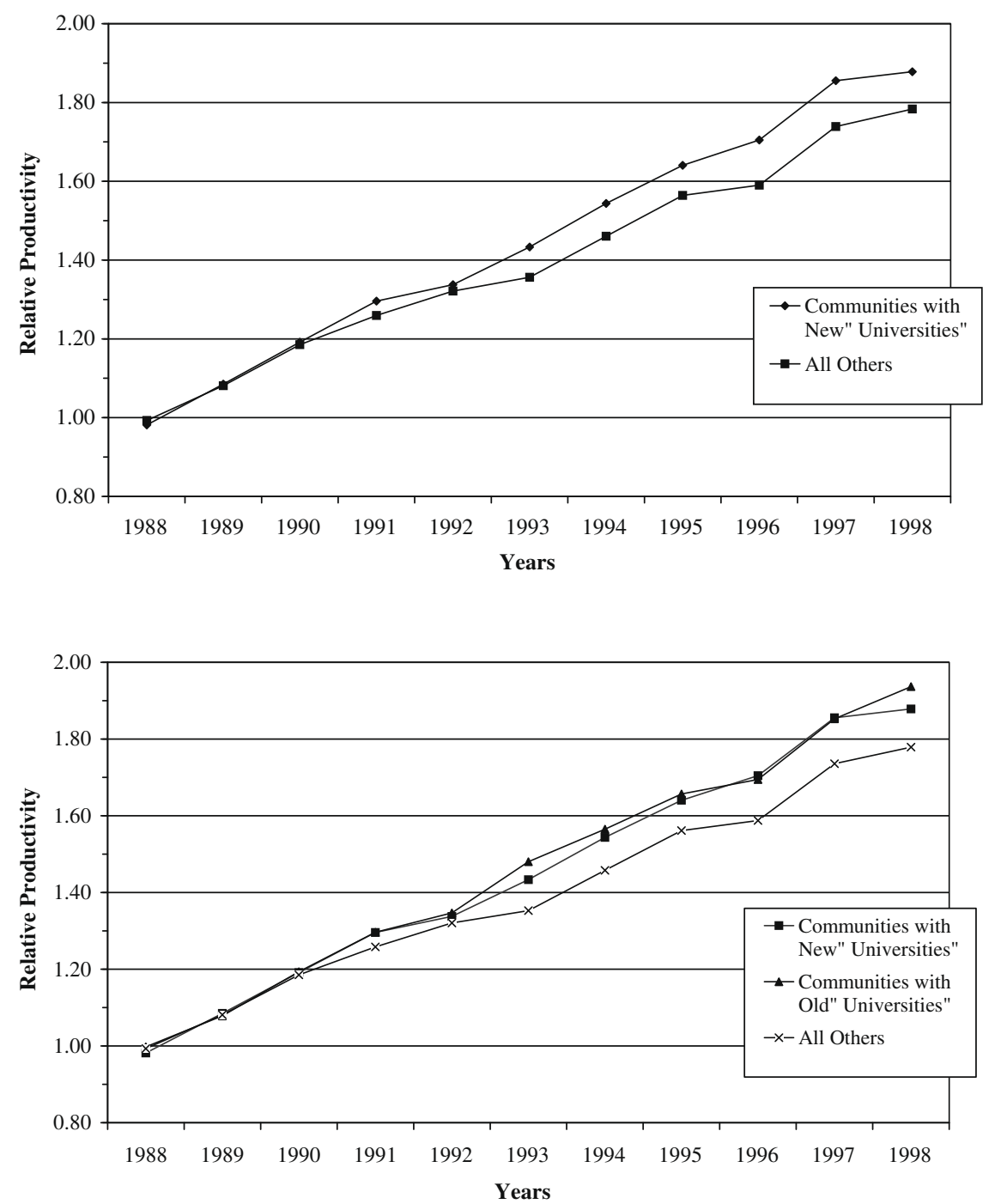

Fig. 5. Relative productivity of communities after establishment of research staff. 
Table 3

Estimated parameters of Poisson models of patent counts 1994-2001 (asymptotic $t$ ratios in parentheses).

\begin{tabular}{|c|c|c|c|c|c|c|}
\hline & & ML estimates & & & IV estimates & \\
\hline & M1 & M2 & M3 & N1 & N2 & N3 \\
\hline$R \times 10^{4}$ & $1.130(4.41)$ & & & $2.873(2.23)$ & & \\
\hline$R^{n} \times 10^{4}$ & & 24.411 (3.08) & & & $69.850(2.27)$ & \\
\hline$R^{o} \times 10^{4}$ & & $0.954(3.70)$ & & & $1.718(1.35)$ & \\
\hline$R^{n}$-technical $\times 10^{4}$ & & & $37.462(2.03)$ & & & $110.655(2.08)$ \\
\hline$R^{o}$-technical $\times 10^{4}$ & & & $2.345(6.33)$ & & & $4.121(2.10)$ \\
\hline Pseudo $R^{2}$ & 0.934 & 0.934 & 0.935 & 0.400 & 0.400 & 0.400 \\
\hline $\log L$ & -1771.147 & -1768.430 & -1760.254 & -1731.768 & -1731.698 & -1730.535 \\
\hline
\end{tabular}

Note: All models include fixed effects for 100 market areas and eight years. The sample consists of a panel of 800 observations on patent counts by labor market area.

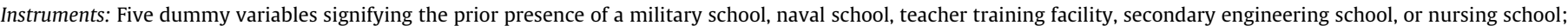

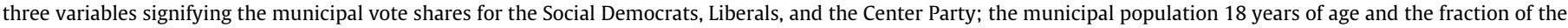
population 18 years of age.

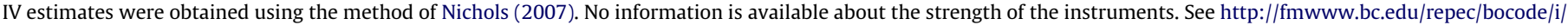
ivpois.sthlp for details.

newer institution increases productivity by $4.0 \%$. Using the analogous logarithmic specification, L11, we estimate an augmentation of 100 post-graduate researchers at an older established university increases productivity by $0.4 \%$ while the equivalent investment at a newer institution increases productivity by $2.5 \%$. These conclusions are robust to estimation by instrumental variables and also to the recognition of spatial factors in the model.

\section{Statistical models of creativity}

We analyze the effects of university decentralization on creativity in a parallel manner, using methods appropriate to the analysis of patent count variables.

We assume that the number of patents, $\eta_{i t}$, awarded in labor market area $i$ in year $t$ is distributed as,

$\operatorname{prob}\left(\eta_{i t}=y_{i t}\right)=\frac{e^{-\mu_{i t} \lambda_{i t}}\left(\mu_{i t} \lambda_{i t}\right)^{y_{i t}}}{y_{i t} !}$,

for $y_{i t}=0,1,2, \ldots$.

In this formulation, the left hand side represents the probability that the number of patents in labor market $i$ and year $t, \eta_{i t}$, equals the number $y_{i t}$.

We further assume that

$\log \lambda_{i t}+\log \mu_{i t}=X_{i t}$

that is, the parameter $\lambda_{i t}$ is $\log$ linear in a vector, $X$, of regressors describing the labor market area $i$ and the time period $t$. If $\mu_{i t}=1$, the mean and the variance of the count distribution are equal, and Eq. (2) is a straightforward Poisson model. If the mean and variance of the count distribution are unequal, the parameters of the model may be represented as an equally straightforward negative binomial count model. ${ }^{18}$ We define a set of regressors,

$X_{i t}=\delta E_{i t}+\sum_{j=1}^{100} \beta_{j} L_{j}+\sum_{k=1994}^{2001} \gamma_{k} T_{k}$,

where $E_{i t}$ characterizes post-secondary educational institutions in labor market area $i$ in year $t . L_{j}$ is an indicator variable with a value of one for labor market area $j=i$ and zero otherwise ${ }^{19} ; T_{k}$ is an indi-

\footnotetext{
18 This follows directly, if it is assumed that $\mu_{i t}$ follows a gamma distribution, $\mu_{i t} \sim \operatorname{Gamma}(1 / \alpha, \alpha)$. If $\alpha=0$, the model is Poisson. If $\alpha>0$, the model is negative binomial.

19 We use 100 labor market areas rather than the 284 cities where inventors reside because inventors may live in one community and work in another within the same metropolitan labor market area.
}

cator variable with a value of one for year $t=k$ and zero otherwise. As before, $\delta, \beta$, and $\gamma$ are parameters.

The effects of university decentralization upon innovative activity are identified by changes in measures of university activity within each labor market area over time. To estimate the model, we include a complete set of fixed effects for each time period and labor market area using a maximum likelihood estimator. As shown by Blundell et al. (2002), HHG, this is equivalent to the conditional maximum likelihood estimator proposed by Hausman et al. (1984). We test whether the estimated variance is equal to the mean (see Cameron and Trivedi, 1998, pp. 282-284) by computing the parameters of the negative binomial model.

We relate the decentralization in educational policy to the level of innovative activity, as measured by patents granted 3 years after the educational investments (see also Fischer and Varga, 2003 and Verspagen and De Loo, 1999). In particular, for each labor market area and year, we record the number of university-employed post-graduate researchers $R_{i t}$. We also record the number of research staff at each university employed in technical research specialties.

Table 3 presents the basic results. The table relates the number of patents in any labor market area and year to the number of postgraduate researchers employed at universities in that labor market. Research staffs are further disaggregated between those employed at new $\left(R^{n}\right)$ and old $\left(R^{o}\right)$ universities for all staff and for those in technical occupations.

Columns 1, 2, and 3 suggest that the number of post-graduate researchers is associated with higher levels of innovative activity, holding constant the important unmeasured characteristics of these differing labor market areas. The total number of patents in these regions is 15,805 during the 1994-2001 period or about 200 per year in a given labor market area. From column 1, the addition of a single post-graduate researcher increases the number of patents in any labor market area by a factor of exp[0.000113] or by almost $0.01 \%$ in any year.

In column 2 (model M2), we disaggregate the research staff by those employed at the old universities and those employed at the new institutions. Both measures are highly significant, but the coefficient estimated for researchers at the new universities $(0.00244)$ is larger by an order of magnitude than the coefficient estimated for researchers at the old established universities. When researchers in scientific and technical occupations are considered separately, the significance of the coefficient measuring post-graduate staff is reduced (to the $5-10 \%$ level for a one-tailed test) at new universities. However, the magnitude of the coefficient for researchers at new universities is again larger by an order of magnitude than is the estimated coefficient for researchers employed at the older institutions. 
Table 3 also presents the results when the Poisson models are estimated by the technique of instrumental variables (see Nichols, 2007, for a discussion of Poisson count models estimated by IV methods). In these models, N1 through N3, we use the same variables as instruments that are used in the models of productivity reported in Table 3 . The results are robust to this more general method of estimation. The magnitudes of the coefficients are larger, suggesting stronger effects upon productivity, but the $t$ ratios of the coefficients are somewhat smaller.

In Appendix Table A1, we generalize the estimation still further, using the negative binomial model. We relax the maintained hypothesis of the Poisson model that the mean and the variance of the count distribution are equal, but we follow HHG in estimating separately a common mean and a common variable for the count distribution. The qualitative results of the model ${ }^{20}$ are similar, but the magnitudes of the coefficients measuring the importance of post-graduate research staffs in affecting patents activity are uniformly larger in these more general models.

Conditional upon the establishment of an educational institution in a region, the marginal effect of an increase in the research staff upon patent activity is not trivial. And the marginal effects on creativity of adding research staff at the new institutions is estimated to be consistently larger than the effects of adding staff at the older, more established institutions.

For example, from model M2 it is estimated that an additional research complement of 10 individuals at a new institution leads to an increase in patents of about $2.4 \%$ while a similar increase in research staff at an older institution leads to an increase in patents of about $0.1 \%{ }^{21}$ This difference does not appear to arise from a different mix of technical and non-technical research staffs at the two institutions. For example, from model M3 which considers only postgraduate researchers in technical specialties, an increase of 10 technicians yields an increase in patents of $3.8 \%$ in the newer institutions and about $0.2 \%$ in the older institutions. ${ }^{22}$ Of course all these comparisons abstract from the many other, and presumably more important, aspects of these different labor market regions which affect creativity and innovation. The fixed effects distinguishing these one hundred labor market areas are large and highly significant in all specifications.

\section{Spillovers, externalities, and interactions}

How localized are the productivity and creativity increases attributable to these public investments? The spatially disaggregated data on individual municipalities and labor market areas provides some opportunity to explore the extent of spatial agglomeration and externalities.

Table 2 hints at the importance of spillovers in productivity gains over space. In all of the statistical models reported, the gravity measure is statistically significant, suggesting the presence of spatial agglomeration. However, the values of Moran's I Statistics are also quite large, suggesting that the simple gravity model does not capture the underlying spatial relationship very well. ${ }^{23}$

\footnotetext{
${ }^{20}$ Note that we have been unable to estimate the negative binomial model using instrumental variables.

21 Specifically, at the point of means, from equation M3 10 additional post-graduate researchers yield 2.05 patents in the new institutions and 0.16 patents in the old institutions.

${ }^{22}$ Note again that we cannot distinguish, in these models, between the direct effects of university resources in stimulating innovation and the indirect effects arising from the location of other facilities in response to the investments in university facilities.

${ }^{23}$ For example, for model L1 Table 3, the value of Moran's I is 8.741. When the model is extended to include the gravity representation of space, in $\mathrm{L} 2$, the value of Moran's I is smaller, 7.823. However this latter value is still highly significant statistically, suggesting the presence of spatial autocorrelation in the data.
}

Table 4

Spatial Autoregressive (SAR) and Spatial Error (SEM) Models of the effects of universities on productivity, by municipality, 1985-1998 (asymptotic $t$ ratios in parentheses).

\begin{tabular}{llllll}
\hline & \multicolumn{2}{c}{ SAR estimates } & & \multicolumn{2}{c}{ SEM estimates } \\
\cline { 2 - 3 } \cline { 5 - 6 } & S1 & S2 & & S3 & S4 \\
\hline$R^{n} \times 10^{4}$ & $2.808(1.97)$ & $3.064(2.16)$ & & $2.888(2.04)$ & $3.043(2.15)$ \\
$R^{o} \times 10^{4}$ & $0.082(1.20)$ & $0.098(1.44)$ & & $0.061(0.91)$ & $0.119(1.75)$ \\
$\mathrm{Gr} \times 10^{4}$ & & $0.944(4.41)$ & & $0.984(4.14)$ \\
$\lambda$ & $0.238(128.36)$ & $0.196(109.80)$ & & $0.239(39.03)$ & $0.182(25.96)$ \\
$\rho$ & & & & \\
\hline
\end{tabular}

Note: Gr represents the coefficient for $\sum_{j \neq i} R_{j t} / d_{i j}^{2}$ where $d_{i j}$ is the distance between communities $i$ and $j$.The sample consists of a panel of 3976 observations on output per worker by municipality and year.

As an alternative, we consider the general spatial lag model, incorporating spatial structure explicitly into the model ${ }^{24}$ :

$$
\begin{aligned}
& \log P_{i t}=\rho \sum_{j \neq i} W_{i j}^{1} \log P_{j t}+E_{i t}+\sum_{j=1}^{284} \beta_{j} M_{j}+\sum_{k=1985}^{1998} \gamma_{k} T_{k}+\varepsilon_{i t}, \\
& \varepsilon_{i t}=\lambda \sum_{j \neq i} W_{i j}^{2} \varepsilon_{i t}+v_{i t} .
\end{aligned}
$$

In this formulation, the productivity of labor in any municipality also depends upon the productivity of labor in neighboring towns. In response to an exogenous change in university investment in one municipality, productivity in neighboring municipalities may be enhanced as well. In the spatial error formulation, $\rho$ indicates that productivity depends directly upon the productivity of other municipalities, where $W_{i j}^{1}$ are the weights. Analogously, the parameter $\lambda$ is the coefficient in the spatial autoregressive structure, and $W_{i j}^{2}$ are the weights for the errors in other municipalities. If there are no a priori reasons to suppose that the spatial interaction patterns are different, then $W_{i j}^{1}=W_{i j}^{2}$, and $\rho$ and $\lambda$ are not separately identified.

In this spatial application, we assume $W_{i j}^{1}=W_{i j}^{2}=1 / d_{i j}^{2}$, that is, we assume that the weight matrix is of the form of the gravity model. (See Anselin, 1988, pp. 16-28.) If $\rho$ defines the autoregressive spatial structure in Eq. (5), $\lambda=0$, we can estimate the Spatial Autoregressive Model (SAR):

$\log P_{i t}=\rho \sum_{j \neq i}\left(1 / d_{i j}^{2}\right) \log P_{j t}+E_{i t}+\sum_{j=1}^{284} \beta_{j} M_{j}+\sum_{k=1985}^{1998} \gamma_{k} T_{k}+\varepsilon_{i t}$.

Alternatively, if $\lambda$ defines the autoregressive spatial structure, $\rho=0$, we can estimate the Spatial Error Model (SEM):

$$
\begin{aligned}
& \log P_{i t}=E_{i t}+\cdots+\varepsilon_{i t}, \\
& \varepsilon_{i t}=\lambda \sum_{j \neq i} \varepsilon_{j t} / d_{i j}^{2}+v_{i t} .
\end{aligned}
$$

Table 4 reports the coefficients of the SAR and SEM models, estimated by maximum likelihood methods, assuming normality of the error terms. As reported in the table, when spatial autocorrelation is recognized in the models, the coefficients of the other variables are reduced in magnitude and statistical significance. But the basic pattern of coefficients is unchanged. The alternate models of spatial autocorrelation yield quite similar results in terms of magnitude and significance. Either measure of spatial dependence, $\rho$ or $\lambda$, is highly significant.

In models relating productivity to the number post-graduate researchers, the coefficient on the number of researchers in the same community is significant. The magnitudes of the coefficients on university researchers are smaller in these models which incor-

\footnotetext{
${ }^{24}$ Anselin et al. (1997) is the standard reference documenting these spatial models.
} 
porate spatial autocorrelation and the broader productivity linkages among municipalities. In all cases, the coefficients indicate that productivity is higher in communities in which more university-based researchers are employed. These results are significant at the 0.15 level. We also find clear evidence that this effect is substantially larger for those researchers employed at the newer institutions than for those employed at the older institutions. Finally, we find that productivity is greater in communities in closer proximity to pools of university-based researchers. This latter finding is consistent with results reported by Adams (2002) for US academic institutions.

Spillovers in creativity are less likely to be uncovered, in part due to the more aggregate representation of space. As noted above, because inventors may live in one municipality and work in another, we can only measure patent counts annually at the level of the labor market area. There are only 100 labor market areas in Sweden (as compared to 284 municipalities), and their boundaries are chosen to maximize the within-area economic relationships relative to the between-area relationships. Nevertheless, it is possible to conduct a parallel effort to test for spatial linkages.

Consider the spatial Poisson model, Eqs. (2)-(4) but in which Eq. (4) is replaced by

$X_{i t}=\xi \sum_{i \neq j} W_{i j}^{3} \eta_{j t}+\delta E_{i t}+\sum_{j=1}^{100} \beta_{j} L_{j}+\sum_{k=1994}^{2001} \gamma_{k} T_{k}$.

In this model, the patent count in any one labor market is related to the patent count in all other labor market areas. As before, $W_{i j}^{3}$ is a weight matrix involving the distances between labor market areas, and $\xi$ is a parameter. A variant of this model, the class of spatial Poisson regression models, is described in Best et al. (2000). ${ }^{25}$ Related models, with epidemiological applications, are discussed in Elliott et al. (2001). The model can be estimated iteratively using Bayesian methods.

Table 5 reports the results of this investigation of potential spillovers in patent activity. We use the nearest neighbor technique ${ }^{26}$ to define the weight matrix, $W^{3}$, again using $1 / d_{i j}^{2}$ as elements of $W_{i j}^{3}$. We investigate the same models analyzed in Table 4 . Parameters of the spatial Poisson model are estimated using Geobugs. ${ }^{27}$ The magnitudes of the estimated coefficients are larger in these estimates, but the pattern of the coefficients is identical to those reported previously. The coefficient of the variable measuring the number of university-affiliated post-graduate researchers is significant, as is the number at new institutions, and the number of technical researchers at new institutions. The coefficient on the number of researchers is consistently higher for the new universities than for the old institutions.

There is no evidence in these results of spatial autocorrelation in the patent counts across labor market areas. The coefficient $\xi$ is not precisely estimated to be zero, that is, its standard error is quite large in all specifications. This contrasts with our finding of spatially correlated productivity effects. Of course, the productivity effects are measured for much smaller geographical units of observation. The regions used for the analysis of patents are both larger $^{28}$ and are designed to maximize the intra-regional economic

\footnotetext{
25 In the application by Best et al. (2000), a slightly different specification of the spatial relationship in $\left(4^{\prime}\right)$ is used to analyze spatial correlation in the distribution of counts measuring the incidence of respiratory ailments across geographical areas. In an analogous application, Ickstadt and Wolpert (1997) analyzed the spatial distribution of hickory trees in different plots situated in a forest.

26 See Anselin (1988) for a through discussion.

27 We are grateful to Nicky Best for making an advance version of release 4.1 available to us for this purpose. In our applications, we use 1000 "burn in" iterations to derive starting values for the coefficients, and we use another 1000 iterations to produce coefficient estimates. Results are insensitive to these choices. These results are also insensitive to the inclusion or exclusion of fixed effects.

28 For example, the Stockholm labor market area includes some 27 municipalities.
}

Table 5

Estimated parameters of spatial Poisson models of patent counts 1994-2001 (asymptotic $t$ ratios in parentheses).

\begin{tabular}{lcrr}
\hline & S1 & S2 & \\
\hline$R \times 10^{3}$ & $5.665(1.95)$ & & \\
$R^{n} \times 10^{3}$ & & $5.994(3.96)$ & \\
$R^{o} \times 10^{3}$ & & $3.826(1.42)$ & \\
$R^{n}$-technical $\times 10^{3}$ & & & $10.470(3.39)$ \\
$R^{o}$-technical $\times 10^{3}$ & & & $1.037(1.52)$ \\
$\xi$ & $4.588(0.00)$ & $0.247(0.00)$ & $1.270(0.00)$ \\
$\log L$ & -6240 & -4312 & -6280 \\
\hline
\end{tabular}

Note: $\xi$ represents the coefficient for $\sum_{j \neq i} W_{i j}^{3} \eta_{j t}$ where $\eta_{j t}$ is the patent count in labor market $j$ in year $t$ and the weight matrix, $W_{i j}^{3}$, is based upon the nearest neighbor method. All models include fixed effects for 100 labor market areas and eight time periods. The sample consists of a panel of 800 observations on patent counts by labor market area and year.

linkages relative to the inter-regional linkages. Thus, it should not be surprising that, at this level of detail, spatial autocorrelation cannot be detected.

Finally, our spatially disaggregated data supports some investigation of the importance of human capital externalities and the absorptive capacity of regions in affecting productivity and creativity. In particular, for each of the labor market areas and municipalities, we can measure the fraction of the labor force with $\mathrm{PhD}$ degrees in each year. Table 6 summarizes the importance of this factor in conditioning the effects of post-graduate university researchers on output per worker and patent activity.

The table reports the results of including a variable measuring the fraction of PhD's in the labor force and its interaction with the number of researchers at old universities. In models of patent counts this measure of labor force quality is generally significant (even in models that include fixed effects for 100 labor market areas). In models of productivity, the coefficient exceeds its standard error but is insignificant (in models that include fixed effects for each of the 284 municipalities). The interpretation of this result is problematic since, as emphasized by Moretti (2004), regional variation in the stock of human capital may simply be endogenous.

However, the results also suggest that the importance of researchers at the new universities in increasing local productivity and creativity is larger in regions with a more highly educated labor force. Regions with higher fractions of educated labor are those where the effects of new universities on productivity and patents is larger. Robustness checks of the count models using the more general negative binomial model are presented in Appendix Table A1. Nothing changes our conclusions.

\section{The attenuation of spillovers}

The models of productivity reported in Tables 2 and 4 support a more detailed investigation of the spatial pattern of productivity spillovers. These results suggest that there are substantial, but highly localized, spillovers in productivity gains over space. Table 7 summarizes the implications of our estimates - based on log linear and logarithmic specifications, OLS and IV estimation, as well as SAR and SEM specifications of spatial errors. The estimates clearly imply that these productivity gains are highly localized. The spillovers from researchers employed at the old established institutions are concentrated; roughly $40 \%$ of the cumulative gain in productivity is within $10 \mathrm{~km}$ of the institution. For the new universities, where the estimated effect on productivity is larger, the attenuation is even more pronounced. Between one-third and one-half of the total effect upon productivity is registered within $5 \mathrm{~km}$ of the university. The numerical estimates vary with the details of the statistical models, but the patterns are the same; a rapid 
Table 6

Estimated interactions between university researchers and the education of the workforce on productivity and creativity (asymptotic $t$ ratios in parentheses).

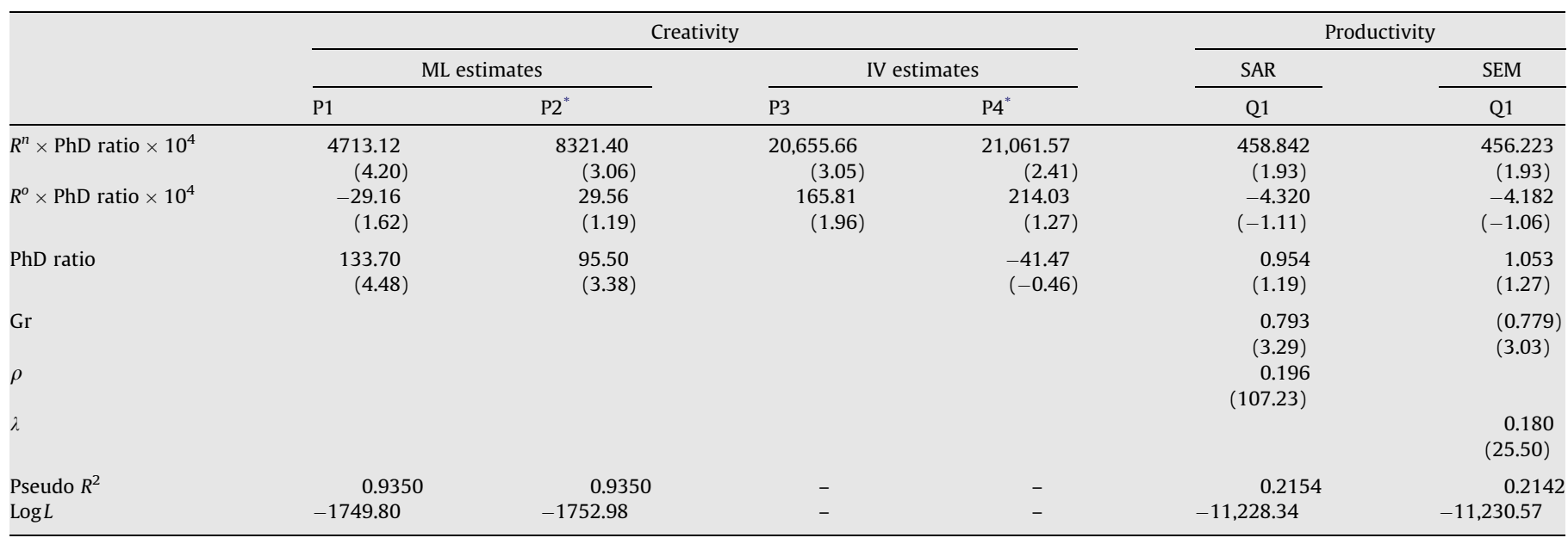

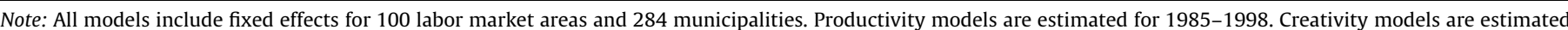
for 1994-2001.

" These models use the number of post-doctoral university researchers in technical specialties and are estimated for $1993-1998$.

fall-off with distance, more rapidly for investments made at the newly established institutions.

These findings are consistent with a growing body of empirical research in other countries on the agglomerative tendencies of socalled "knowledge industries." Saxenian (1994), for example, suggested that knowledge generated at a firm in the US is more likely to spill out locally if it originates in a small firm. Conversely, Henderson's analysis (2003) of US high tech industry at the plant level suggests that smaller firms are more likely to benefit from local agglomeration. Rosenthal and Strange (2003) found that small establishments in the knowledge industry have larger effects on locational attractiveness than larger ones. In an earlier paper using micro data from Dunn and Bradstreet, they also found (Rosenthal and Strange, 2001) that proxies for knowledge spillovers in the US affect firm agglomeration only at the very local (postal code) level. Two other analyses of US industry suggest that local externalities and agglomerative economies greatly attenuate with distance. Rosenthal and Strange (2005) analyzed manufacturing, trade and services in New York, finding that agglomerative effects on firm births and employment decline rapidly over space. (They attribute this attenuation to the "high costs of moving ideas" over space.) They also analyzed nationally representative data for the US (Rosenthal and Strange, 2008), finding that the effect of urbanization economies on worker productivity may be only about half as large at distances over $8 \mathrm{~km}$ as it is at closer distances. (See also Agrawal et al. (2008).)

The results of our analysis of Swedish productivity are consistent with these findings. We find highly significant, but highly localized, external effects arising from the geographical locations chosen for these new institutions of higher education.

Finally, it is also possible, at least in principle, to estimate the net change in output and patent activity arising from the spatial rearrangement of researchers. Using the results presented in Table 3 , for example, the level of innovation in each region can be computed under the counterfactual of no decentralization of Swedish universities. To do this, we reallocate the researchers, employed in the 25 newly established institutions during the period 19952001, back to the 11 institutions which had been in existence in 1987. We reallocate researchers to the pre-existing institutions in proportion to their distribution in 1987. A comparison of this counterfactual with actual inventive activity yields the net change in patents arising from the decentralization of higher education.
Using the coefficients in model N3 in Table 3, we estimate that the net effect of this spatial rearrangement on patents to be about zero. We can also use the results presented in Tables 2 and 4 to estimate the level of productivity under the counterfactual of no decentralization of Swedish universities. (We use the same counterfactual, and again, we reallocate researchers to the pre-existing institutions in proportion to their distribution in 1987.) Data on the number of workers in each municipality allow us to compare the value of total output with output under the counterfactual. A comparison of this counterfactual with realized output yields the net change in GDP arising from the policy of decentralizing higher education. Using the same six statistical models reported in Table 7, we estimate the net effect of this spatial arrangement to be an increase in GDP of between $0.01 \%$ and $0.10 \%{ }^{29}$ These calculations suggest that the increment to GDP is, in fact, quite large. Indeed, it is roughly as large as the initial contribution to GDP of these workers.

\section{Conclusion}

During the past 15 years, Swedish higher education policy encouraged the decentralization of post-secondary education. We investigate the spatial and economic effects of this decentralization on productivity and creativity. We provide several tests of the hypothesis that the establishment or expansion of university research in a region improves productivity and enhances creativity. We find systematic evidence that output per worker is higher and the award of patents is greater in regions that have received larger university-based investments as measured by the number of researchers employed on staff. We also find that changes in productivity are higher and new patent awards are more frequent in regions in which the "new" universities and institutions are located than in regions in which the "old" universities are located.

Our analysis permits us to hold constant the important factors affecting economic activity by municipality, labor market area and time, thereby improving the precision of estimates. The results are broadly consistent across theoretical models and statistical

\footnotetext{
29 Specifically the estimated increase in GDP arising from the university decentralization, as computed from each of these six models is: $0.01 \%$ (L4); $0.01 \%$ (L8); $0.04 \%$ (L12); 0.05\% (L16); 0.11\% (S2); 0.07\% (S4).
} 


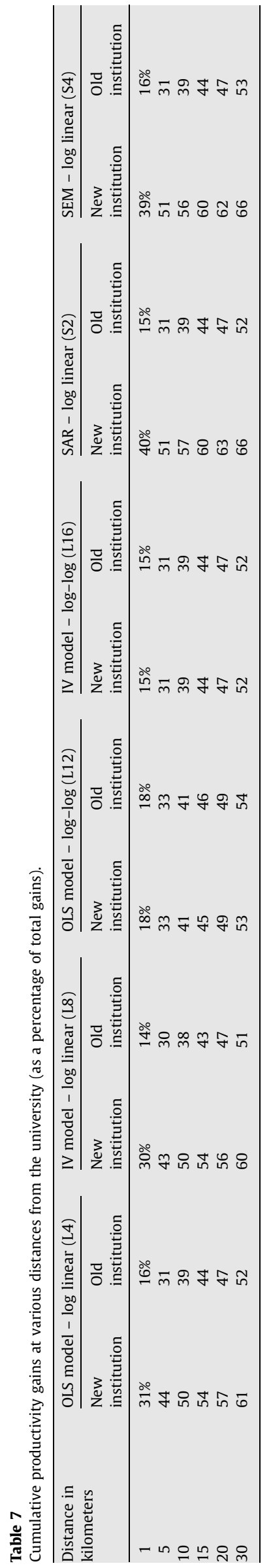

results. There is strong evidence that an expansion of university presence in a community, measured by the number of university-based researchers, is associated with increased output per worker in that community and with increases in the patents awarded to inventors in that labor market area.

The importance of the university in affecting productivity and creativity is consistently larger at the margin for the new institutions. For patents, at least, this could arise if the new institutions specialize more narrowly in technical specialties than do the more traditional institutions of higher education. Of course, some of the new institutions are, in fact, expansions of institutions that formerly provided some technical training (e.g., military facilities). This may explain some of the differences. ${ }^{30}$

The productivity gains are highly localized. The spillovers from researchers employed at the old established institutions are concentrated. Roughly $40 \%$ of the cumulative gain in productivity is within $10 \mathrm{~km}$ of the institution. For the new universities the attenuation is even more pronounced; between one-third and one-half of the total effect upon productivity is registered within $5 \mathrm{~km}$ of the university.

Our findings are consistent with a substantial, but highly attenuated, external effect of investment in higher education, augmenting the productivity of local areas and the local economies in which they are situated.

\section{Appendix A}

Table A1

Negative binomial estimates of patent counts corresponding to Poisson estimates reported in Tables 3 and 6.

\begin{tabular}{|c|c|c|c|c|c|}
\hline & \multicolumn{3}{|l|}{ Table 3} & \multicolumn{2}{|l|}{ Table 6} \\
\hline & M4 & M5 & M6 & P3 & $\mathrm{P} 4^{*}$ \\
\hline$R \times 10^{4}$ & $\begin{array}{l}2.293 \\
(3.71)\end{array}$ & & & & \\
\hline$R^{n} \times 10^{4}$ & & $\begin{array}{l}25.635 \\
(2.52)\end{array}$ & & & \\
\hline$R^{o} \times 10^{4}$ & & $\begin{array}{l}1.739 \\
(2.91)\end{array}$ & & & \\
\hline$R^{n}$-technical $\times 10^{4}$ & & & $\begin{array}{l}49.078 \\
(2.21)\end{array}$ & & \\
\hline$R^{o}$-technical $\times 10^{4}$ & & & $\begin{array}{l}3.267 \\
(3.76)\end{array}$ & & \\
\hline$R^{n} \times \mathrm{PhD}$ ratio $\times 10^{4}$ & & & & $\begin{array}{l}4621.71 \\
(2.89)\end{array}$ & $\begin{array}{l}8918.23 \\
(2.61)\end{array}$ \\
\hline$R^{o} \times \mathrm{PhD}$ ratio $\times 10^{4}$ & & & & $\begin{array}{l}10.15 \\
(0.29)\end{array}$ & $\begin{array}{l}69.39 \\
(1.34)\end{array}$ \\
\hline PhD_ratio & & & & $\begin{array}{l}78.38 \\
(1.82)\end{array}$ & $\begin{array}{l}64.15 \\
(1.57)\end{array}$ \\
\hline Alpha & $\begin{array}{l}0.014 \\
(5.32)\end{array}$ & $\begin{array}{l}0.013 \\
(3.98)\end{array}$ & $\begin{array}{l}0.012 \\
(3.72)\end{array}$ & & \\
\hline Pseudo $R^{2}$ & 0.400 & 0.400 & 0.400 & 0.401 & 0.401 \\
\hline $\log L$ & -1731.76 & $8-1731.69$ & $8-1730.535$ & -1728.30 & -1728.56 \\
\hline
\end{tabular}

Note: All models include fixed effects for 100 labor market areas and 284 municipalities.

P4 uses the number of post-doctoral university researchers in technical specialties and is estimated for 1993-1998.

\footnotetext{
${ }^{30}$ Without conducting a more anthropological investigation, it is not possible to resolve this. But some collateral information is suggestive of a more commercial and industrial orientation among (some) of the new institutions. Thus, Karlstad University (http://www.kau.se/research/forests.lasso) in the heart of the Swedish pulp and paper region boasts a substantial research program in "Forests, environment, and materials," and Luleå University (http://www.ltu.se/inst) has an institute of "Applied Physics..." and another of "Applied Chemistry...."
} 


\section{References}

Acs, Z., Anselin, L., Varga, A., 2002. Patents and innovation counts as measures of regional production of new knowledge. Research Policy 31 (7), 1069-1085.

Adams, J.D., 2002. Comparative localization of academic and industrial spillovers. Journal of Economic Geography 2 (3), 253-278.

Agrawal, A., Kapur, D., McHale, J., 2008. How do spatial and social proximity influence knowledge flows? Evidence from patent data. Journal of Urban Economics 64 (2), 258-269.

Andersson, R., 2005. The efficiency of Swedish regional policy. Annals of Regional Science 39 (4), 811-832.

Andersson, R., Quigley, J.M., Wilhelmsson, M., 2004. University decentralization as regional policy: the Swedish experiment. Journal of Economic Geography 4 (4), 371-388.

Anselin, L., 1988. Spatial Econometrics: Methods and Models. Kluwer Academic Publishers, Dordrecht.

Anselin, L., Varga, A., Acs, Z., 1997. Local geographic spillovers between university research and high technology innovations. Journal of Urban Economics 42 (3), 422-448.

Arzaghi, M., Henderson, J.V., 2006. Networking off Madison Avenue, unpublished paper.

Audretsch, D., Feldman, M., 1996. R\&D spillovers and the geography of innovation and production. American Economic Review 86 (3), 630-640.

Best, N.G., Ickstadt, K., Wolpert, R.L., 2000. Spatial Poisson regression for health and exposure data measured at disparate resolutions. Journal of the American Statistical Association 95 (452), 1076-1088.

Blundell, R., Griffith, R., Windmeijer, F., 2002. Individual effects and dynamics in count data models. Journal of Econometrics 108, 113-131.

Cameron, A., Trivedi, C., Trivedi, P.K., 1998. Regression Analysis of Count Data. Cambridge University Press, Cambridge, UK.

De första 20 åren. Utvecklingen vid de mindre och medelstora högskolorna sedan 1977 1998. Högskoleverket (National Agency for Higher Education), Stockholm.

Elliott, P., Wakefield, J., Best, N., Briggs, D., 2001. Spatial Epidemiology: Methods and Applications. Oxford University Press, Oxford.

Feldman, M., 1994. The Geography of Innovation. Kluwer Academic Publishers, Boston, MA.

Fischer, M.M., Varga, A., 2003. Spatial knowledge spillovers and university research: evidence from Austria. Annals of Regional Science 37, 303-322.

Florax, R., 1992. The University: A Regional Booster? Aldershot, Avebury.

Fujita, M., 1988. A monopolistic competition model of spatial agglomeration: a differentiated product approach. Regional Science and Urban Economics 18 (1), 124-187.

Glaeser, E.L., Kallal, H.D., Scheinkman, J.A., Shleifer, A., 1992. Growth in cities. Journal of Political Economy 100 (6), 1126-1152.

Greenstone, M., Hornbeck, R., Moretti, E., 2008. Identifying agglomeration spillovers: evidence from million dollar plants. NBER Working Paper 13833.

Griliches, Z., 1979. Issues in assessing the contribution of R\&D to productivity growth. Bell Journal of Economics 10 (1), 92-116.

Griliches, Z., 1984. R\&D, Patents and Productivity. University of Chicago Press, Chicago, IL.

Griliches, Z., 1990. Patent statistics as economic indicators: a survey. Journal of Economic Literature XXVIII, 1661-1707.

Griliches, Z., 1998. R\&D and Productivity. University of Chicago Press, Chicago, IL.
Grossman, G.M., Helpman, E., 1991. Innovation and Growth in the Global Economy. MIT Press, Cambridge, MA.

Hausman, J.A., Hall, B.H., Griliches, Z., 1984. Econometric models for count data with applications to the patents-R and D relationship. Econometrica 52, 909-938.

Henderson, J.V., 2003. Marshall's scale economies. Journal of Urban Economics 53 (1), 1-28

Henderson, J.V., Kuncoro, A., Turner, M., 1995. Industrial development in cities. Journal of Political Economy 103 (5), 1067-1090.

Ickstadt, K., Wolpert, R.L., 1997. Multiresolution assessment of forest inhomogeneity. In: Gatsonis, C. et al. (Eds.), Case Studies in Bayesian Statistics, vol. III. Springer, Berlin, pp. 371-386.

Jaffe, A., 1986. Technological opportunity and spillovers of R\&D: evidence from firms patents, profits and market value. American Economic Review 76, 984-1001.

Jaffe, A., 1989. Real effects of academic research. American Economic Review 79, 957-970.

Jaffe, A., Trajtenberg, M., Henderson, R., 1993. Geographic localization of knowledge spillovers an evidenced by patent citations. Quarterly Journal of Economics 434, 578-598.

Jaffe, A., Trajtenberg, M. (Eds.), 2002. Patents, Citations \& Innovations. A Window on the Knowledge Economy. MIT Press, Cambridge, MA.

Krugman, P., 1991. Increasing returns and economic geography. Journal of Political Economy 99 (3), 483-499.

Lucas, R., 1988. On the mechanics of economic development. Journal of Monetary Economics $22(1), 3-42$.

Marshall, A., 1890. Principles of Economics. McMillan Co., London.

Moretti, E., 2004. Human capital externalities in cities. In: Henderson, J.V., Thisse, J.F. (Eds.), Handbook of Regional and Urban Economics. Elsevier North Holland Amsterdam, pp. 2243-2292.

Nichols, A., 2007. IVPOIS: Stata Module to Estimate and Instrumental Variables Poisson Regression Via GMM, Econ Papers. Available from: http:// econpapers.repec.org/software/bocbocode/s456890.htm.

Rauch, J.E., 1993. Productivity gains from geographic concentration of human capital: evidence from the cities. Journal of Urban Economics 34 (3), 380-400.

Romer, P., 1986. Increasing returns and long-run growth. Journal of Political Economy 94 (5), 1002-1037.

Romer, P., 1990. Endogenous technological change. Journal of Political Economy 98, 71-102.

Rosenthal, S.S., Strange, W.C., 2001. The determinants of agglomeration. Journal of Urban Economics 50, 191-229.

Rosenthal, S.S., Strange, W.C., 2003. Geography, industrial organization, and agglomeration. Review of Economics and Statistics 85 (2), 377-393.

Rosenthal, S.S., Strange, W.C., 2005. The Geography of Entrepreneurship in the New York Metropolitan Area, unpublished paper.

Rosenthal, S.S., Strange, W.C., 2008. The attenuation of human capital spillovers. Journal of Urban Economics 64, 373-389.

Saxenian, A., 1994. Regional advantage: culture and competition in Silicon Valley and Route 128. Harvard University Press, Cambridge, MA.

Varga, A., 1998. University Research and Regional Innovation. Kluwer Academic Publishers, Boston, MA.

Varga, A., 2000. Local academic knowledge transfers and the concentration of economic activity. Journal of Regional Science 40 (2), 289-309.

Verspagen, B., De Loo, I., 1999. Technology spillovers between sectors and over time. Technological Forecasting and Social Change 60, 215-235 